\title{
A SIMPLE MODEL OF A PLUTONIUM NITRATE CONCENTRATOR
}

\author{
R. B. Rozsa \\ S. J. Underwood
}

February 2, 1979

This work was supported by the U.S. Nuclear Regulatory Coinmission under interayency. Agreement DOE $40 \cdot 550-75$ with the U.S. Department of Energy.

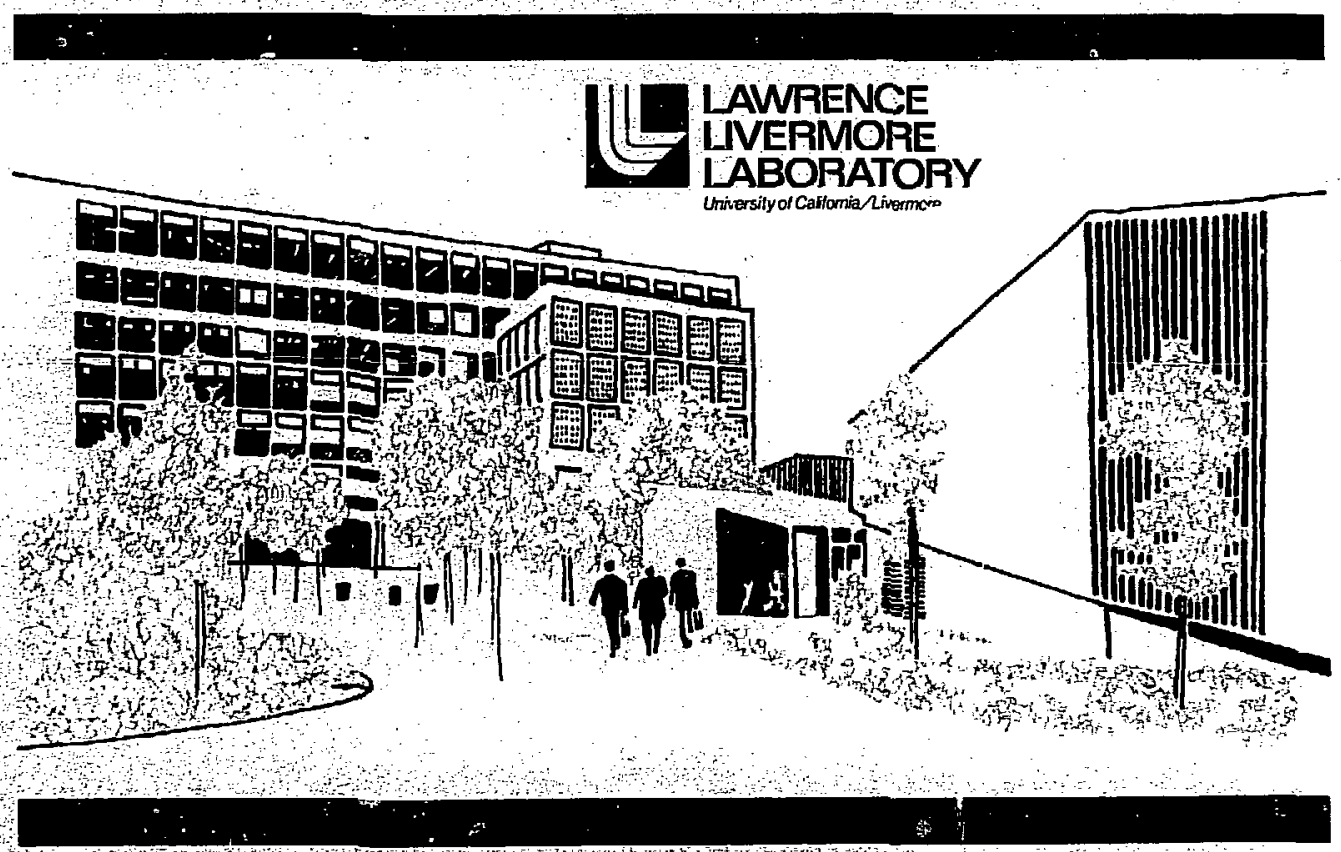




\title{
㢟 \\ LAWRENCE LJVERMORE LABORATORY \\ Universityol Caltomia/Livermore, Calfornia/ 94550
}

UCRL - 52711

\section{A SIMPLE MODEL OF A PLUTONIUM NITRATE CONCENTRATOR}

\author{
R. B. Rozsa \\ S. J. Underwood \\ Now at University of California, Chemical Engineering Department
}

Manuscript date: February 2, 1979

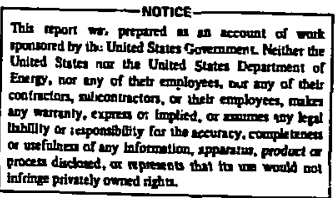

infinge pivately owned ingti. 


\section{CONTENTS}

Nomenclature

Abstract . . . . . . . . . . . . . . . . . . . . . . ix

Introduction

Discussion

Concentrator (complex mode1)

Concentrator (simple model)

Madel Equations . . . . . . . . . . . . . . . . 4

Solution Technique . . . . . . . . . . . . . . . 6

Closed Form Solution . . . . . . . . . . . . . . . . 7

Sample Calculations . . . . . . . . . . . . . . . . 7

Summary and Conclusions . . . . . . . . . . . . . . . . . 14

Acknowledgment . . . . . . . . . . . . . . . . . 15

Appendix A: Converting the Conservation Equations

to State Variable Equations . . . . . . . . . . . . . 17.

Appendix B: Material Properties . . . . . . . . . . . . . . 21

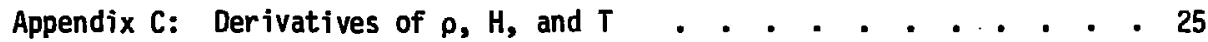

Appendix D: User's Guide to the Code . . . . . . . . . . . . 27

Appendix E: Code Listing (microfiche) . . . . . . . . . . . 37

References . . . . . . . . . . . . . . . . . . . 39 


\section{LIST OF ILLUSTRATIONS}

1. Plutonium nitrate evaporator/concentrator . . . . . . . . . 3

2. Reduced plutonium nitrate evaporator/concentrator model . . . . . 5

3. Pertubations from steady-state conditions . . . . . . . 8

4. Plot of selected variables vs time for start up conditions $0-6 h$. . 11

5. Plot of selected variables vs time for various input parameters

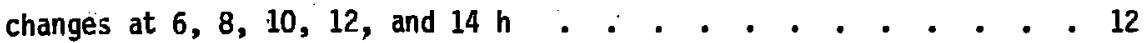




\section{NOMENCLATURE}

$a_{j}$ - Empirical constants in equation $B-1$

$b_{j}$ - Empirical constants in equation $B-2$

$c_{j}$ - Empirical constants in equation $B-4$

$d_{j}$ - Empirical constants in equation B-6

f( ) - Functional relationship involving ( )

$\mathrm{H} \quad$ - Enthalpy of tank solution $\mathrm{J} / \mathrm{g} \mathrm{mol}$

$H_{s}$ - Enthalpy of feed, $\mathrm{J} / \mathrm{g} \mathrm{mol}$

$H_{s}$ - Enthalpy of steam, $\mathrm{J} / \mathrm{g} \mathrm{mol}$

$H_{v}$ - Enthalpy of vapor, $\mathrm{J} / \mathrm{g} \mathrm{mol}$

$\mathrm{H}^{*} \quad-\mathrm{dH} / \mathrm{dt}$, derivative with respect to time

$M_{f}$ - Feed flow rates, $g$ mol/h

$M_{0}$ - Overflow rate, $g \mathrm{~mol} / \mathrm{h}$

$M_{s}$ - Steam rate, $g \mathrm{~mol} / \mathrm{h}$

$M_{v}$ - Vapor flow rate, $g \mathrm{~mol} / \mathrm{h}$

P - Pressure, Pa

$P_{S}$ - Steam pressure, $\mathrm{Pa}$

$Q$ - Steam heat flow rate, $J / h$

$t$ - time, $h$

T - Temperature, ${ }^{\circ} \mathrm{C}$

$U_{N}$ - Mole fraction $\mathrm{HNO}_{3}$ in feed

$U_{p}$ - Mole fraction $\mathrm{Pu}\left(\mathrm{NO}_{3}\right)_{4}$ in feed

$v^{p}$ - Volume, $m^{3}$

$v_{0}$ - Volume of tank at overflow, $\mathrm{m}^{3}$

$X_{N}$ - Mole fraction $\mathrm{HNO}_{3}$ in tank, product

$X_{p}$ - Mole fraction $\mathrm{Pu}\left(\mathrm{NO}_{3}\right)_{4}$ in tank, product

$Y_{N}$ - Mole fraction $\mathrm{HNO}_{3}$ in vapor

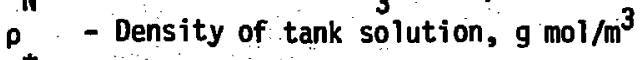

$\rho^{*} \quad-d \rho / d t$, derivative with respect to time

(') $-d() / d t$, derivative of state variable with respect to time 
A simplc mathematical model of a plutonium nitrate evaporator/concentrator is described and computer code calculations are tested against results from a more complex model. The computer code is capable of computing transient responses of the system to arbitrary stimuli input by the user in an interactive mode. The mode 1 is described in detail including mass and energy conservation equations as well as boundary conditions and other system constraints. A closed form solution which is valid under restricted conditions is also described. The results show agreement within a few percent between the simple and complex model calculations. 


\section{INTRODUCTION}

Lawrence Livermore Laboratory (LLL) is conducting a safeguards program for the Nuclear Regulatory Commission. One task of the Material Control Project of this program is to develop a methodology for assessing materia! control and accounting methods (MCA) in chemical plants that handle special nuclear material (SNM). As part of this task, we have undertaken mathematical modeling of some of the chemical process operations that typically take place in these plants. The objective is twofold: (1) To simulate experimental data and (2) to provide simple estimator models for simulating on-line process monitors. The first objective is motivated by the lack of pertinent data and the expense of obtaining many different sets of experimental data for studying material diversion scenarios. The second objective is due to the need for reduced-order models for studying on-line estimator/detector applications. The latter model must necessarily be simple since the estimator algorithms use it repetitively during their functioning. (See Candy and Rozsa ${ }^{1}$ for an example.)

In this report we describe a simple model of a plutonium nitrate evaporator/ concentrator and concrast it with a more complex detailed model of a unit similar to one at the Barnwell, S.C. Plant of Allied General Nuclear Services (AGNS). Although this work is discussed in the context of a plutonium nitrate evaporator/concentrator, it is representative of a class of thermosiphon concentrator components that are generic to any fuel cycle involving chemical separations/purifications 


\section{DISCUSSION}

CONCENTRATOR (COMPLEX MODEL)

The plutonium nitrate evaporator/concentrator (sometimes called thermosiphon reboiler) is depicted in Fig. 1. The unit increases the concentration of plutonium nitrate in an aqueous acid liquid phase by evaporating the water and acid out of solution. Low concentrate $\mathrm{Pu}\left(\mathrm{NO}_{3}\right)_{4}$ enters the feed line in solution with water and nitric acid and mixes with the process stream in the reboiler (heat exchanger). The reboiler heats and partially vaporizes the solution which then flows to he vapor separator. The vapor exits at the top after passing through a demister and the liquid settles to the bottom. The demister prevents liquid from being drawn off with the vapor. Periodically, the demister is washed with nitric acid to eliminate plutonium nitrate buildup. The major fraction of the liquid in the separator is recycled through the reboiler loop. Recirculation of the process stream occurs because of the difference in effective density in the reboiler and separator. The liquid level in the separator is essentially the same height as the overflow pipe. The flow rate through the reboiler adjusts by natural circulation to a level such that the pressure drop due to the density difference is equivalent to the frictional drop.

A detailed model of this evaporator/concentrator was developed by Frogner and Rande $11^{2}$ under contract to LLL. This complex 10-state or more ${ }^{*}$ nonlinear dynamic model with nonlinear algebraic constraint equations includes two-phase mass and heat transfer and accounts for temperature and pressure variations throughout the system. The number of state variables coupled with the small time constant of the recirculation loop causes the code calculations to run slowly in certain cases (many minutes for simulating hours of real time). For

\footnotetext{
* The reboiler was partitioned into nodes that increase the number of state equations depending on the grid desired.
} 


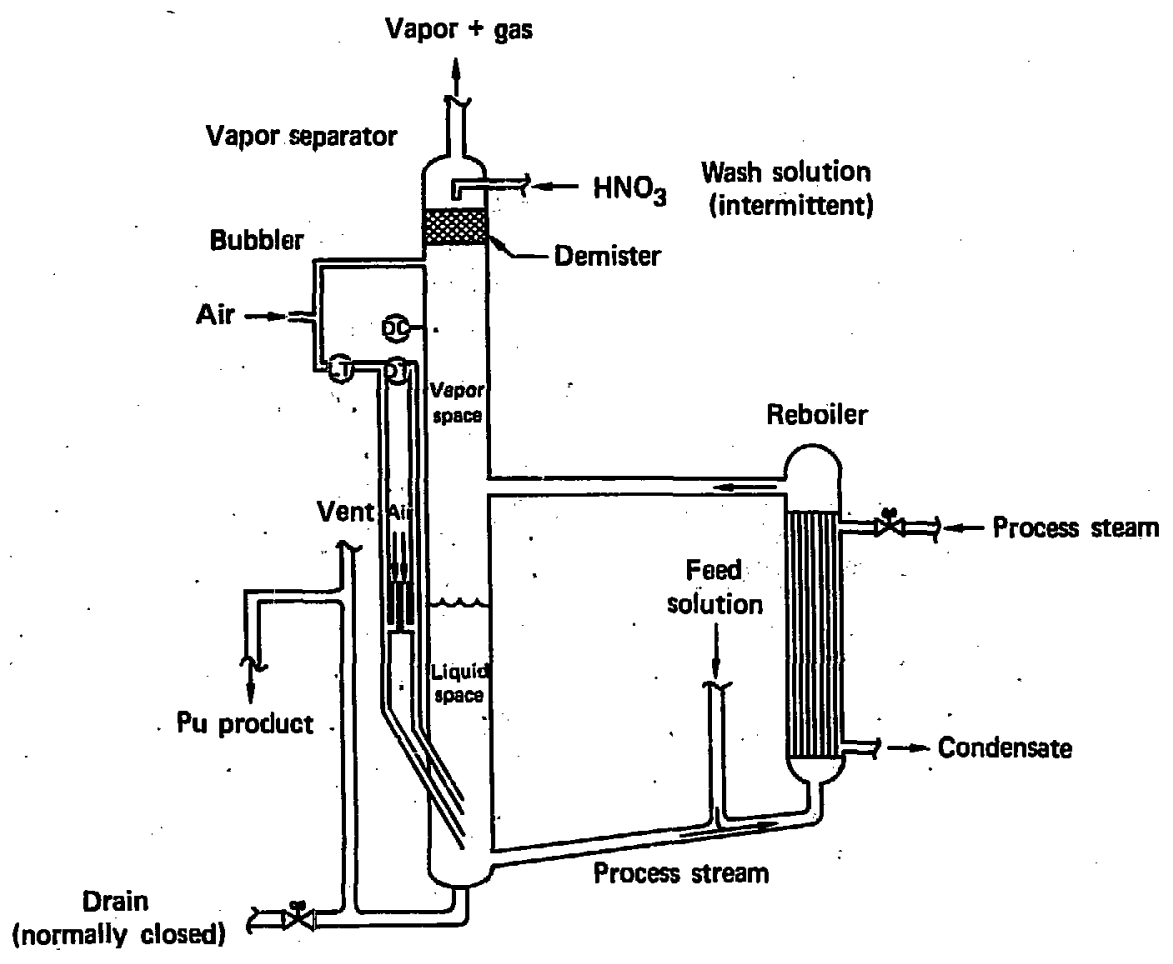

FIG. 1. Plutonium nitrate evaporator/concentrator. 
sinulating experimental data, the code is quite adequate; in fact, this level of detaii allows sophisticated diversion scenarios to be investigated involving the recirculation loop response to upsets. However, for inclusion in simulation codes such as DYNSYL ${ }^{3}$ (a complex process simulator) or DYNEST $^{4}$ (an estimator) this version is too complicated.

\section{CONCENTRATOR (SIMPLE MODEL)}

A simpler model that retains many of the important features of the unit is showm in Fig. 2. Here, we lump the separator and the recirculation loop into one volume and assume instantaneous head and mass transfer (well-mixed tank assumption). He also assume a constant pressure in the unit and include the nitric acid wash effects in the feed stream composition. From an overall mass and energy balance view, these assumptions are reasonable since the high rate of recirculation ensures rapid mixing and heat transfer in the system. The time constant of the simple model is dominated by the mass capacity of the unit and is much larger than that of the more complex model thereby allowing larger integration time steps to be taken.

MODEL EQUATIONS:

He describe the system in terms of species' mass balances, an energy balance, and several empirical relationships of density, temperature, and composition. These are similar to those used by Frogner and Randa $11^{2}$ and are shown in detail in Appendix $B$.

The final form for the $\mathrm{Pu}\left(\mathrm{NO}_{3}\right)_{4}$ and $\mathrm{HNO}_{3}$ mole fractions is as follows:

$$
\dot{x}_{p}=\frac{\left(M_{v}-M_{f}\right) x_{p}+M_{f} U_{p}}{\rho V}
$$

$$
\dot{x}_{N}=\frac{\left(M_{V}-M_{f}\right) x_{N}+M_{f} U_{N}-M_{V} Y_{N}}{\rho V} \text {. }
$$

where 


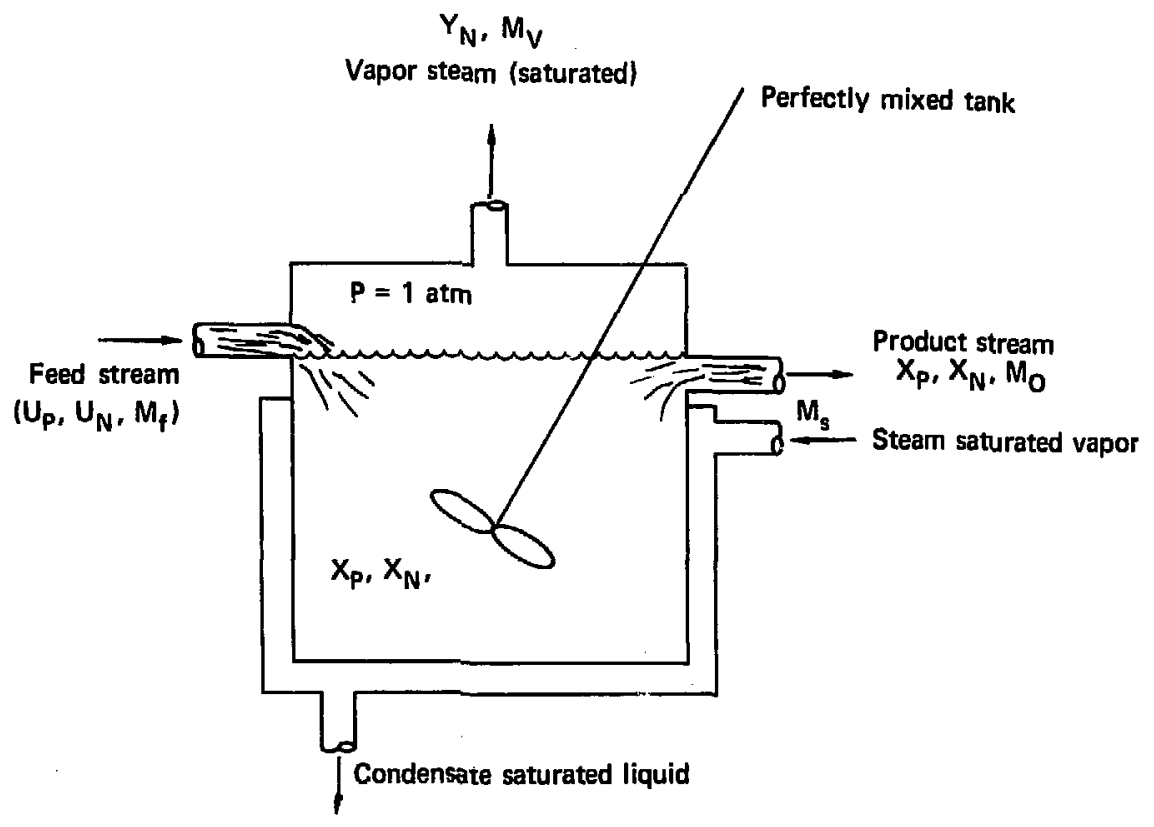

FIG. 2. Reduced plutonium nitrate evaporator/concentrator model. 


$$
\begin{aligned}
& \text { (i) }=\frac{\mathrm{d}()}{\mathrm{dt}} \\
& t=\text { time, } h \\
& \text { p = the liquid density in the vessel }\left(\mathrm{g} \mathrm{mol} / \mathrm{m}^{3}\right) \\
& V=\text { the volume of the vessel }\left(\mathrm{m}^{3}\right) \\
& M_{f}, M_{v}=\text { the feed and vapor flow rates }(\mathrm{gmol} / \mathrm{h}) \\
& U_{p}, X_{p}=\text { the feed and product mole fraction of } \mathrm{Pu}\left(\mathrm{NO}_{3}\right)_{4} \text { in the } \\
& \text { liquid phase } \\
& \dot{\mathrm{U}}_{\mathrm{N}} ; \mathrm{X}_{\mathrm{N}}=\text { the feed and product mole fraction of } \mathrm{HNO}_{3} \text { in the liquid } \\
& \text { phase } \\
& Y_{N} \quad=\text { the mole fraction of } \mathrm{HNO}_{3} \text { in the vapor phase. }
\end{aligned}
$$

The overflow pipe constrains the volume $V \leq V_{0}$ where $V_{0}$ is the maximum or overflow volume. If the level is less than the overflow height another description for volume is needed:

$$
\dot{v}=\frac{M_{f}-M_{v}-\rho^{*} v}{\rho} \quad \begin{aligned}
& \text { for } v<v_{0} \text { or } \\
& \text { for } v=v_{0} \text { and } \dot{v}<0 .
\end{aligned}
$$

The above system [Eqs. (1-3)] is a two-state model when overflow is occurring and a three-state model when there is no overflow.

$M_{f}, U_{p}$ and $U_{N}$ are input values normally. $M_{V}$ is determined by the energy balance (Appendix $A$ ), $\rho$ is determined through an empirical relationship in $X_{p}$ and $X_{N}$ (Appendix $B$ ), and ${ }^{*}$ is calculated by formally differentiating Q the expression for $\rho$ (Appendix $C$ ). These algebraic relationships for $M_{v}, \rho$, and $\rho^{*}$ are complex and nonlinear and are solved

\section{SOLUTION TECHNIQUE}

The three ordinary differential equations are nonlinear by virtue of the above My, $p$, and $\rho^{*}$ relationships. We use solution techniques incorporated in a code version developed at $L L L{ }^{5}$ This version has several options which Include solution of stiff systems using techniques pioneered by Gear. Our set 
is not stiff under normal conditions and will allow calculation of simulation times of 10-20 h in 2-5 s for overflowing cases and 5-20 s for nonoverflowing cases using a simple Adams ${ }^{5}$ method with functional iteration.

CLOSED FORM SOLUTION

Under certain conditions the equations for plutonium nitrate may be integrated directly. If the system is overflowing $\left(V=V_{0}\right)$ and $\rho$ and $M_{v}$ do not vary significantly, direct integration of Eq. 1 is possible:

$$
\frac{\left(x_{p}+\frac{M_{f} U_{p}}{M_{v}-M_{f}}\right)}{\left(x_{p}+\frac{M_{f} U_{p}}{M_{v}-M_{f}}\right)_{0} t=t_{0}}=\operatorname{Exp}\left[\left(\frac{M_{f}-M_{v}}{\rho V_{0}}\right)\right] t .
$$

The above expression is identical to the one that Frogner and Randa $11^{2}$ found by fitting their numerical results to an exponential curve. They obtained three different time constants depending on whether they perturbed the initial plutonium feed composition $\left(U_{p}\right)$ or the steam rate (changes $M_{v}$ ) or feed flow rate $\left(M_{f}\right)$. They thought this was due to nonlinearities in the model. The above time constant, $\left(M_{f}-M_{v} / \rho V_{0}\right)^{-1}$ is indeed different for the three perturbations, but is still basically a turnover time (capacity/net outfiow).

\section{SAMPLE CALCULATIONS}

To compare the results of the complex, simple, and closed form models, we calculated three cases where steady state conditions were perturbed about $10 \%$ in certain boundary or input conditions. Figure 3 compares the results calculated using the models for three cases perturbed from nominal steady state conditions. Table 1 gives the steady state conditions used in the calculation of the three cases. The agreement between all three models is excellent (within 2\%). The density variation for the complex and simple models during these runs was about $2 \%$ for case $A$ and about $10 \%$ for cases $B$ and $\mathrm{C}$. We should also note that the $\mathrm{Pu}\left(\mathrm{NO}_{3}\right)_{4}$ mole fraction from 


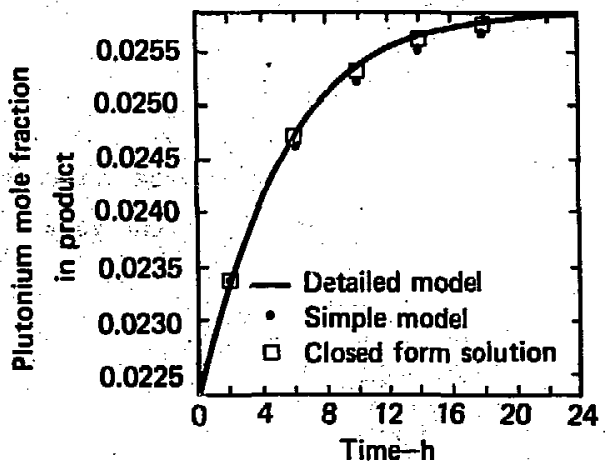

Case A: $\mathrm{Pu}\left(\mathrm{NO}_{3}\right)_{4}$ mole fraction in feed changed to 0.005 $\rho \sim 4.5 \times 10^{4} \mathrm{~mol} / \mathrm{m}^{3}$

Case B: Feed flow rate changed to $1804 \mathrm{~mol} / \mathrm{h}$ $\rho \sim 4.2 \times 10^{4} \mathrm{~mol} / \mathrm{m}^{3}$

Case C: Vaporization rate changed to $1729 \mathrm{~mol} / \mathrm{h}$ $\rho \sim 4.3 \times 10^{4} \mathrm{~mol} / \mathrm{m}^{3}$

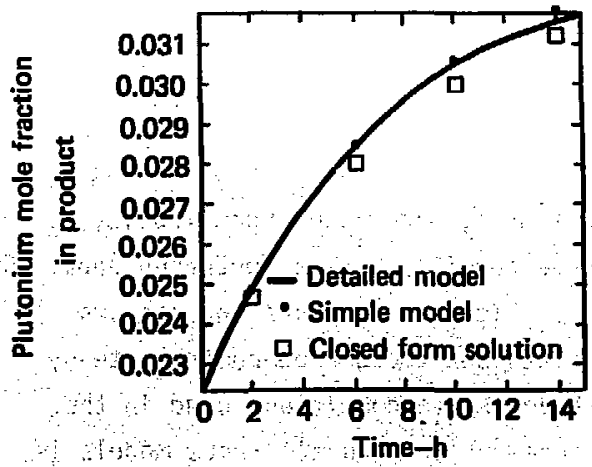

FIG: 3. Pertubations fron steady-state conditions. 
TABLE 1. Steady-state conditions.

Feed rate $=1988 \mathrm{~mol} / \mathrm{h}$
$\mathrm{PU}\left(\mathrm{NO}_{3}\right)_{4}$ mole fraction
$=0.0043$
$\mathrm{HNO}_{3}$ mole fraction
$=0.0098$
$\mathrm{H}_{2} \mathrm{O}$ mole fraction
$=0.9869$

Vaporization rate $=1603 \mathrm{mcl} / \mathrm{h}$

Tank vol $=0.048 \mathrm{~m}^{3}$

$\begin{array}{ll}\mathrm{PU}\left(\mathrm{NO}_{3}\right)_{4} \text { mole fraction } & =0.0223 \\ \mathrm{HNO}_{3} \text { mole fraction } & =0.0377 \\ \mathrm{H}_{2} \mathrm{O} \text { mole fraction } & =0.9400\end{array}$

the detailed model has not been averaged to reflect the fluid in the recirculation loop--about $20 \%$ of the total. In Fig. 3 we only compare the $\mathrm{Pu}\left(\mathrm{NO}_{3}\right)_{4}$ mole fraction. Other variables of interest such as density, temperature and vaporization rate, and vapor composition are also in good agreement between the simple and detailed model. The closed form solution does not give these other variables.

To illustrate most of the options available to the user in the interactive mode, we ran the simple model code for a series of operational changes. Table 2 gives the startup conditions. 
TABLE 2. Startup conditions.

Tank conditions:

$$
\begin{aligned}
& v=0.0025 \mathrm{~m}^{3} \\
& x_{p}=0.005 \\
& x_{n}=0.063
\end{aligned}
$$

Feed conditions:

$$
\begin{aligned}
& M_{f}=2000 \cdot \mathrm{mol} / \mathrm{h} \\
& U_{p}=0.005 \\
& U_{n}=0.063
\end{aligned}
$$

Steam conditions:

$$
\begin{aligned}
& P_{s}=0.2 \mathrm{MPa} \\
& M_{s}=1750 . \mathrm{mol} / \mathrm{h} \\
& \left(M_{v} \sim 1600 \mathrm{~mol} / \mathrm{h}\right)
\end{aligned}
$$

Step 1: Startup--filling the unit while evaporating water and acid. Time: $0-6 \mathrm{~h}$. Figure 4 shows the results for $\mathrm{Pu}\left(\mathrm{NO}_{3}\right)_{4}$ and HNO mole fraction, density, temperature, product flow, and leve1. (Note that most variables reach equilibrium rapidly even though the tank itself takes about $5 \mathrm{~h}$ to filit and reach final conditions.)

Step 2: Feed rate increased for $2 \mathrm{~h}$. Time: $6-8 \mathrm{~h}$.

Step 3: Feed composition changed for $2 \mathrm{~h}$. Time: 8-10 h.

Step 4: Steam rate changed for $2 \mathrm{~h}$. Time: $10-12 \mathrm{~h}$.

Step 5: Tank level reduced instantly. Time: 12-14 h.

Step 6: Feed rate and composition changed to drop tank level. Time: 14-16 in.

Figure 5 shows steps 1 through 6 for selected variables vs time. Table 3 lists the time/feature relationships at $6,8,10,12$, and $14 \mathrm{~h}$. 

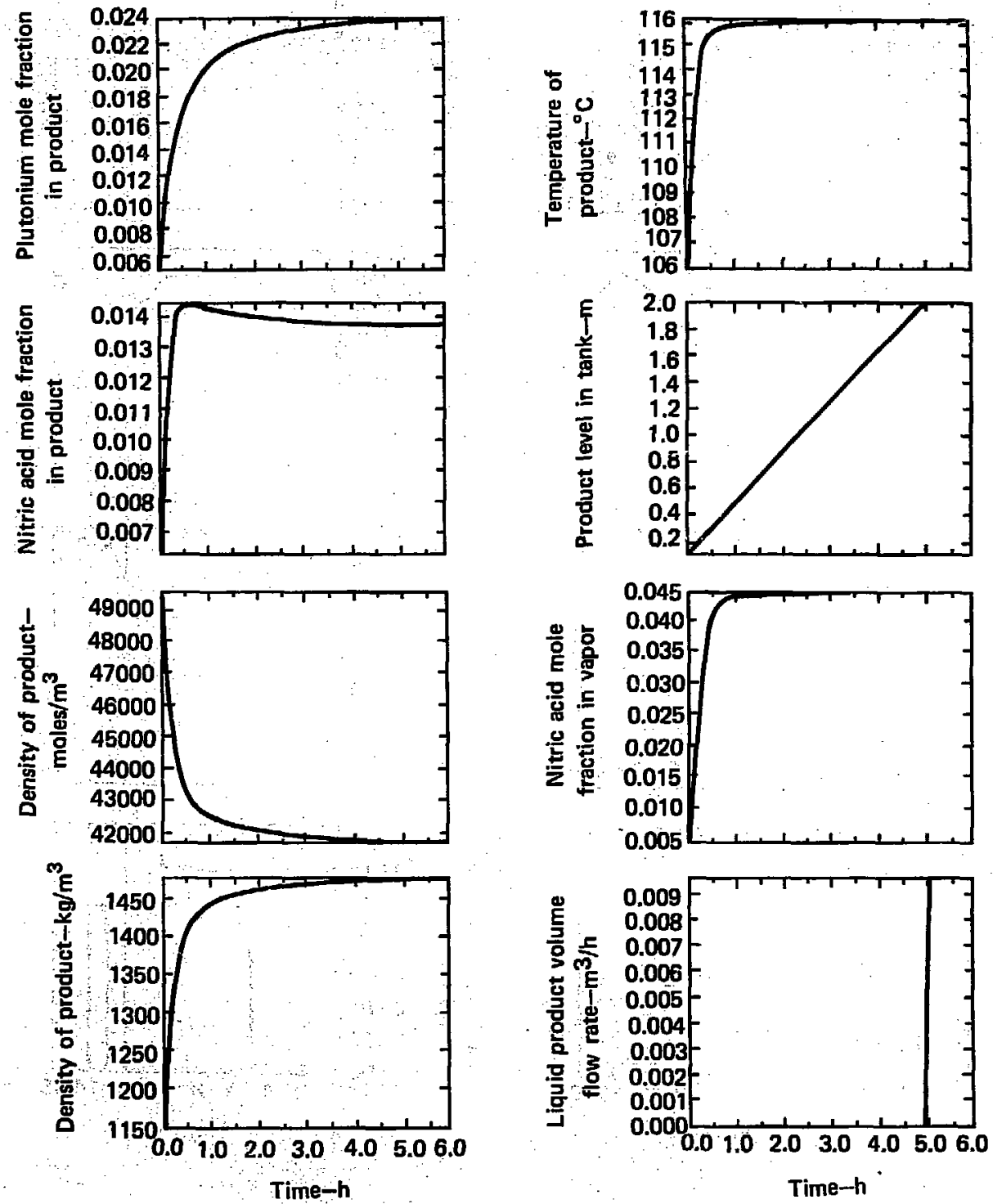

FIG. 4. Plot of selectes variables vs time for startup conditions $0-6 \mathrm{~h}$ $\left(V_{0}=0.050 \mathrm{M}^{3}\right.$, Feed temp $\left.=30^{\circ} \mathrm{C}\right)$. 

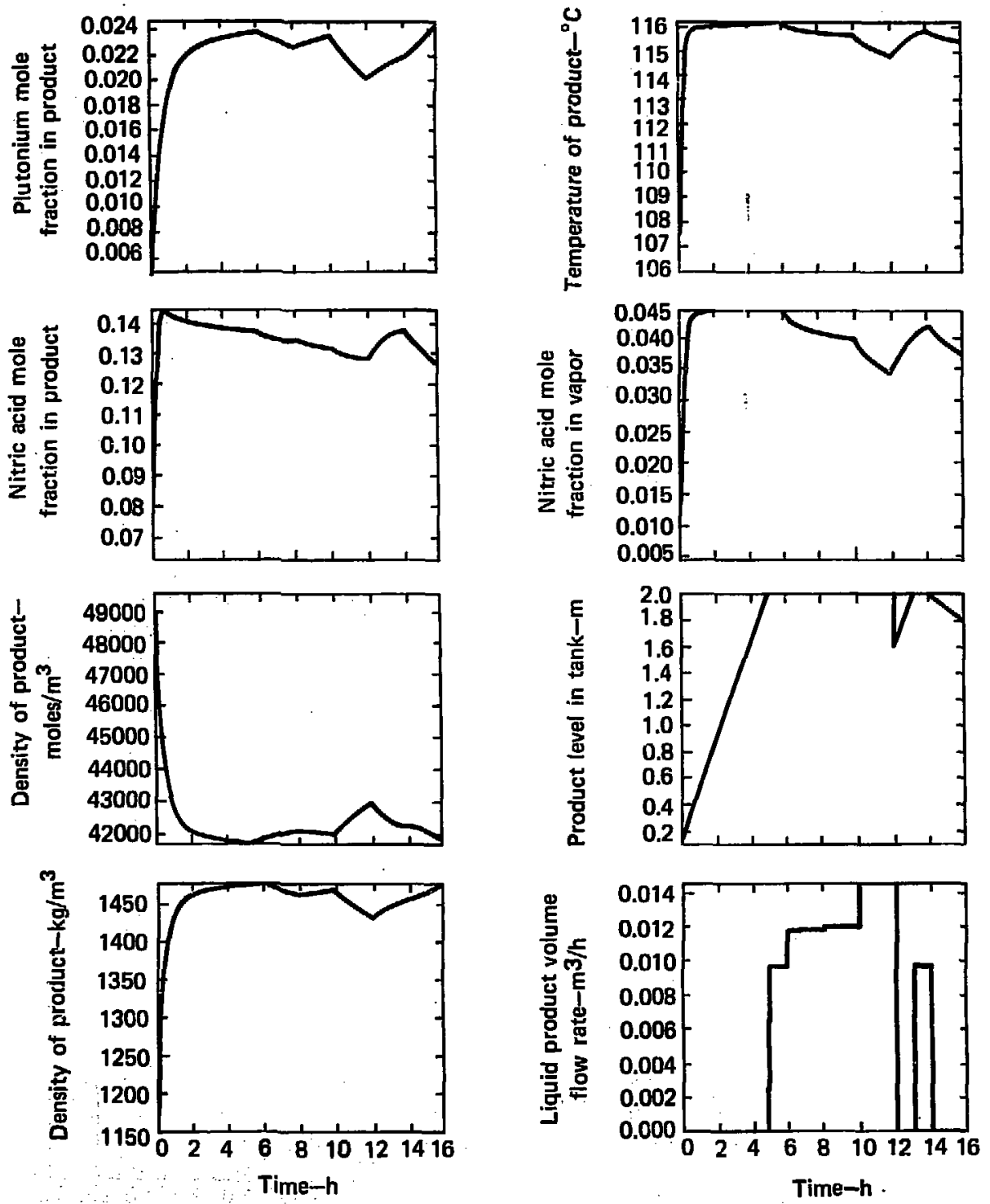

F1G. 5. Plot of selected variables vs time for various input parameters changes at $6,8,10,12$, and $14 h^{*}$

(Refer to Table 4 for exact conditions.) 
TABLF. 3. Time/feature relationships.

\begin{tabular}{ll}
\hline Time, $h$ & \multicolumn{1}{c}{ Feature } \\
\hline $0-5$ & Start up from $5 \%$ tank volume \\
$6-8$ & Feed rate increased $5 \%$ \\
$8-10$ & Pu $\left(\mathrm{NO}_{3}\right)_{4}$ feed comp increased $20 \%$ \\
$10-12$ & Steam rate decreased $8 \%$ \\
$12-14$ & Tank level reduced $20 \%$ at $\mathrm{t}=12 \mathrm{~h}$ \\
$1.4-16$ & $\begin{array}{l}\text { Feed rate and composition changed } \\
\text { to drop tank level }\end{array}$ \\
\hline
\end{tabular}

Table 4 summarizes the graphical results calculated for a series of operational steps. These steps do not necessarily represent actual operating procedures but are intended to show the types of parameter changes allowed in the code.

TABLE 4. Tank, feed, and steam conditions for the results in Figs. 4 and 5.

\begin{tabular}{|c|c|c|c|c|c|c|c|}
\hline \multirow[t]{2}{*}{ Time, $h$} & \multicolumn{3}{|c|}{ Tank conditions } & \multicolumn{3}{|c|}{ Feed conditions $\left(T=30^{\circ} \mathrm{C}\right)$} & \multirow{2}{*}{$\frac{\text { Steam condition }}{M_{s}(\mathrm{~mol} / \mathrm{h})}$} \\
\hline & $x_{p}$ & $x_{n}$ & $v\left(m^{3}\right)$ & $U_{p}$ & $U_{N}$ & $M_{f}(m o l / h)$ & \\
\hline 0 & 0.005 & 0.063 & 0.0025 & 0.005 & 0.063 & 2000.0 & 1750.0 \\
\hline 6 & 0.024 & 0.138 & 0.050 & 0.005 & 0.063 & 2100.0 & 1750.0 \\
\hline 8 & 0.023 & 0.135 & 0.050 & 0.006 & 0.061 & 2099.0 & 1750.0 \\
\hline 10 & 0.024 & 0.132 & 0.050 & 0.005 & 0.063 & 2100.0 & 1600.0 \\
\hline 12 & 0.020 & 0.128 & 0.040 & 0.005 & 0.063 & 2000.0 & 1750.0 \\
\hline 14 & 0.022 & 0.138 & 0.050 & 0.0001 & 0.024 & 1508.0 & 1750.0 \\
\hline
\end{tabular}

The user has the option of changing feed rate, composition, steam flow, volume of liquid in the tank or any combination of these. In addition, graphics may be generated for any increment of time. Figure 4 is for $0-6 \mathrm{~h}$ and Fig. 5 is 0-16 $\mathrm{h}$. Time increments such as $0-8 \mathrm{~h}$ or $10-14 \mathrm{~h}$ can also be selected. This feature allows the user to selectively magnify certain effects or restart problem conditions at will. (See Appendix $E$ for a detailed example of multiple case generaition.) 
We have developed a simple model of a plutonium nitrate concentrator and graphically compared its calculated results with both a more complex model and a closed form solution. Agreement within $2 \%$ between all three is shown in predicting $\mathrm{Pu}\left(\mathrm{NO}_{3}\right)_{4}$ mole fractions. The complex model permits a more exhaustive examination of the internal fluid flow and heat transfer at the expense of computer time. The simple model calculates the essential features of the unit (plutonium inventory) in very short computer times and is suitable as either a stand alone interactive code or in special purpose master codes such as process simulators or estimator/detector codes. 


\section{ACKNOWLEDGMENT}

The authors thank J. V. Candy for his many stimulating conversations and constructive suggestions. 


\section{APPENDIX A}

CONVERTING THE CONSERVATION EQUATIONS TO STATE VARIABLE EQUATIONS

We start formulating our solution for the simple unit shown in Fig. 2 by writing two species' mass balances, an overall mass balance, and an energy balance around the tank volume: See nomenclature for symbols.

$$
\begin{aligned}
& {\left[\mathrm{Pu}\left(\mathrm{NO}_{3}\right)_{4}\right] \quad\left(\rho \mathrm{PX}_{p}\right)=M_{f} U_{p}-M_{0} X_{p}} \\
& {\left[\mathrm{HNO}_{3}\right]} \\
& \left(\rho \dot{v} X_{N}\right)=M_{f} U_{N}-M_{O} X_{N}-M_{V} Y_{N} \\
& \text { [overall] } \\
& \text { (piv) }=M_{f}-M_{0}-M_{v} \\
& \text { [energy] } \\
& (P \dot{V} H)=M_{f} H_{f}-M_{0} H-M_{v} H_{v}+Q
\end{aligned}
$$

We also have some auxiliary relationships (Appendix B) for equilibrium liquid-vapor mole fractions:

$$
Y_{N}=f_{1}\left(x_{p}, x_{N}\right)
$$

liquid density:

$$
\rho=f_{2}\left(X_{p}, X_{N}, T\right)
$$

atmospheric boiling temperature:

$$
T=f_{3}\left(x_{p}, x_{N}, \rho\right), \text { and }
$$

enthalpy:

$$
H=f_{4}\left(x_{P}, x_{N}, T\right)
$$


With this set, we have nine uniknowns:

$\rho, V, X_{p}, X_{N}, Y_{N}, H, T, M_{0}, M_{V}$, and the above eigh': independent relationships plus the overflow constraint on $M_{0}$ and $V$. To arrive at a more compact form, we first differentiate the left hand sides of Eqs. $A-1, A-2$, and $A-4$ and eliminate ( $\rho \dot{V})$ using Eq. A-3. $M_{0}$, an unknown, also drops out and we have, after dividing by $\mathrm{pV}$ :

$$
\begin{aligned}
& \dot{x}_{p}=\frac{M_{f} U_{p}-\left(M_{f}-M_{v}\right) x_{p}}{\rho V}, \\
& \dot{x}_{n}=\frac{M_{f} U_{N}-\left(M_{f}-M_{V}\right) x_{N}-M_{V} Y_{N}}{\rho V} \text {, and } \\
& \dot{H}=\frac{M_{f} H_{f}-\left(M_{f}-M_{v}\right) H-M_{v} H_{V}+Q}{\rho V} .
\end{aligned}
$$

Differentiating the left hand side of Eq. A-3 and substituting the derivative of Eq. A-6 (Appendix C) to el iminate $\rho$, we obtain:

$$
\dot{v}=\frac{M_{f}-M_{v}-M_{0}-\dot{V f}_{2}}{\rho} .
$$

From the overflow constraint, we see that if $V<V_{0}, M_{0} \equiv 0$ and

$$
\dot{v}=\frac{M_{f}-M_{v}-\dot{v f_{2}}}{\rho} .
$$

If $v=v_{0}, \dot{v} \equiv 0$ and the overflow rate is

$$
M_{0}=M_{f}-M_{v}-\dot{v f}_{2} .
$$


Equations $A-9, A-10$, and $A-13$ give state variables as function of known variables with the exception of $M_{v}$. We use Eq. A-11 to solve for $M_{v}$ by substituting the derivative of Eq. A-8 (Appendix $C$ ) to eliminate $H$ and Eq. A-8 and similar relationships to eliminate $H_{v}, H_{f}$ and $H . M_{v}$ is a complicated function of $X_{p}, X_{N}, T$ and their derivatives. Using Eqs. A-6 and $A-7$ and the derivative of Eq. A-7 (Appendix $C$ ), $M_{v}$ is finally given as a function of $X_{p}, X_{N}$ and their derivatives:

$$
M_{v}=\frac{\rho v_{f 4}^{*}-M_{f}\left(H_{f}-H\right)-Q}{\left(H-H_{v}\right)} .
$$

He now have our final set of equations:

STATE VARIABLES

EQUATION

$$
\begin{aligned}
& \dot{x}_{\rho}=\frac{M_{f} U_{p}-\left(M_{f}-M_{V}\right) x_{p}}{\rho V} \\
& \dot{x}_{N}=\frac{M_{f} U_{N}-\left(M_{f}-M_{V}\right) x_{N}-M_{V} Y_{N}}{\rho V} \\
& \dot{v}=\frac{M_{f}-\dot{M}_{V}-\dot{V f}_{2}}{\rho}
\end{aligned}
$$

AUXILIARY RELATIONSHIPS

$$
\begin{aligned}
Y_{N} & =f_{1}\left(x_{p}, x_{N}\right) \\
\rho & =f_{2}\left(x_{p}, x_{N}, T\right) \\
T & =f_{3}\left(x_{p}, x_{N}, \rho\right) \\
H & =f_{4}\left(x_{p}, x_{N}, T\right) \\
M_{V} & =f_{5}\left(\rho, V, M_{f}, H_{f}, H_{V}, Q\right)
\end{aligned}
$$


The auxiliary relationships are non linear and implicit in many of the variables. This requires tteration to find the solutions. For instance, Eqs. $A-6$ and $A-7$ are iterated to find the correct density and temperature for a given $X_{p}$, and $x_{N} \cdot M_{V}$ is a function of both variables and derivatives of variables, and so Egs. A-6 through A-10 and A-15 are iterated until a solution for $x_{p}, x_{N}$ and $M_{v}$ is found. Fortunately, many of the o relationships are weak and direct substitution during iterations allows convergence to the correct values in just a few cycles. 


\section{MATERIAL PROPERTIES}

We use empirical expressions typical of those of Frogner and Rande11, 2 modified slightly to conform with our variables.

EQUILIBRIUM LIQUID-VAPOR MOLE FRACTION ${ }^{6}$

where

$$
Y_{N}=\frac{A}{1-\left(X_{N}+X_{P}\right)^{2}+A} \text {, }
$$

$$
A=x_{N}\left(x_{N}+x_{p}\right)\left(10\left(a_{1}+a_{2}\left(x_{N}+x_{p}\right)^{1 / 2}+a_{3}\left(1-2 x_{N}-x_{p}\right)+a_{4} x_{p}\right)\right)
$$

and

$$
\begin{aligned}
& a_{1}=1.3723 \\
& a_{2}=-0.7936 \\
& a_{3}=-1.3705 \\
& a_{4}=9.0
\end{aligned}
$$

DENSITY OF THE LIQUID SOLUTION 7

$\rho^{2}\left(b_{1} x_{p} x_{N}+b_{2} x_{p}^{2}\right)+\rho\left(b_{3} x_{p}+b_{4} x_{N}+b_{5} x_{p} T+b_{6}\right)+a_{7}+a_{8} T=0$,

where

$$
\begin{array}{ll}
b_{1}=1.856 E-6 & b_{5}=-5.569 E-4 \\
b_{2}=-3.628 E-5 & b_{6}=-1.802 E-2 \\
b_{3}=-2.028 E-2 & b_{7}=1.005 E+3 \\
b_{4}=-1.862 E-2 & b_{8}=-3.158 E-1
\end{array}
$$


from the quadratic formula:

$$
\rho=\frac{-B-\sqrt{B^{2}-4 A C}}{2 A},
$$

where

$$
\begin{aligned}
& A=b_{1} x_{p} x_{N}+b_{2} x_{p}^{2} \\
& B=b_{3} x_{p}+b_{4} x_{N}+b_{5} x_{p} T+b_{6} \\
& C=b_{7}+b_{8} T .
\end{aligned}
$$

The other root is extraneous.

THE ONE ATMOSPHERE BOILING TEMPERATURE

$$
T=c_{1}+c_{2} \rho x_{p}+c_{3} \rho x_{N}+c_{4} \rho^{2} x_{N} x_{p}+c_{5} \rho^{2} x_{p}^{2}+c_{6} \rho^{2} x_{N}^{2},
$$

where

$$
\begin{aligned}
& c_{1}=1.0 \mathrm{E}+2 \\
& c_{2}=5.025 \mathrm{E}-3 \\
& c_{3}=1.223 \mathrm{E}-3 \\
& c_{4}=4.119 \mathrm{E}-7 \\
& c_{5}=2.079 \mathrm{E}-7 \\
& c_{6}=6.042 \mathrm{E}-8 .
\end{aligned}
$$

ENTHALPY AS A FUNCTIOH OF TEMPERATURE

The enthalpy of any phase is the sum of the individual species' enthalpies:

$$
H=\sum_{i=1}^{n} x_{i} H_{i}
$$


and each specie's enthalpy is given by

$$
H i=d_{1}, i+d_{2}, i T+d_{3}, i T^{2},
$$

where the $d_{i}$ 's are given below.

\begin{tabular}{|c|c|c|c|c|}
\hline Species & & $d_{1}$ & $d_{2}$ & $d_{3}$ \\
\hline & $\left.\mathrm{Pu}^{\mathrm{PNO}} \mathrm{N}_{3}\right) 4$ & 0. & 110.8 & 0. \\
\hline Liquids & $\mathrm{HNO}_{3}$ & 0. & 75.54 & 0. \\
\hline & $\mathrm{H}_{2} \mathrm{O}$ & 0. & 75.54 & 0. \\
\hline Vapor & $\mathrm{HNO}_{3}$ & $5.936 E+4$ & 55.51 & 0. \\
\hline & $\mathrm{H}_{2} \mathrm{O}$ & $4.506 E+4$ & 33.23 & $3.855 E-3$ \\
\hline
\end{tabular}

ENTHALPY RELEASED FROM STEAM ।

As a function of saturation pressure we assume

$$
\begin{aligned}
H_{S A T}=e_{1}+e_{2} p_{S}+e_{3} p_{S}{ }^{2} & +e_{4} p_{S}^{3} \\
& \quad \text { for }\left(1.45 E+5 \leq P_{S} \leq 3.8 E 5\right),
\end{aligned}
$$

where $\quad P_{S}=$ saturation pressure $\left(H / M^{2}\right)$

and

$$
\begin{aligned}
& e_{1}=2.331 E+6 \\
& e_{2}=-0.896 \\
& e_{3}=1.484 E-6 \\
& e_{4}=1.209 E-12
\end{aligned}
$$

The energy delivered to the unit at a fixed $P_{S}$ is then

$$
Q=(H 5 A T) M_{S}
$$




\section{APPENDIX C}

\section{DERIVATIVES OF $\rho, H$ AND $T$}

As described in Appendix $A$, we need the derivatives of $\rho, H$, AND $T$ in order to complete our auxiliary expressions. To calculate these, we formally differentiate the appropriate equations in Appendix B. (See Appendix B for the appropriate constants.)

\section{DENSITY OERIVATIVE}

$$
\begin{aligned}
2 \rho \dot{\rho}\left(b_{1} x_{p} x_{N}+b_{2} x_{p}^{2}\right) & +\rho^{2}\left(b_{1}\left(\dot{x}_{p} x_{N}+x_{p} \dot{x}_{N}\right)+2 b_{2} x_{p} \dot{x}_{p}\right) \\
+ & \dot{\rho}\left(b_{3} x_{p}+b_{4} x_{N}+b_{5} x_{p} T+b_{6}\right) \\
& +\rho\left(b_{3} \dot{x}_{p}+b_{4} \dot{x}_{N}+b_{5}\left(\dot{x}_{p} T+\dot{T} x_{p}\right)+a_{8} \dot{\tau}=0\right.
\end{aligned}
$$

Collecting the terms we obtain:

$$
\dot{p}=\frac{-p^{2}\left(b_{1}\left(\dot{x}_{p} x_{N}+x_{p} \dot{x}_{N}\right)+2 b_{2} x_{p} \dot{x}_{p}\right)-\rho\left(b_{3} \dot{x}_{p}+b_{4} \dot{x}_{N}+b_{5}\left(\dot{x}_{p} T+\dot{x}_{p}\right)\right)}{2 p\left(b_{1} x_{p} x_{N}+b_{2} x_{p}^{2}\right)+\left(b_{3} x_{p}+b_{4} x_{N}+b_{5} x_{p} T+b_{6}\right)}
$$

TEMPERATURE DERIVATIVE

$$
\begin{aligned}
\dot{T}=c_{2}\left(\dot{\rho} x_{p}+\rho \dot{x}_{p}\right) & +c_{3}\left(\dot{\rho x_{N}}+\dot{p}_{N}\right)+c_{4}\left(2 \rho \dot{\rho} x_{N} x_{p}+\rho^{2} \dot{x}_{N} x_{p}+\rho^{2} x_{N} \dot{x}_{p}\right) \\
& +c_{5}\left(2 \rho \dot{\rho} x_{p}^{2}+\rho^{2} 2 x_{p} \dot{x}_{p}\right)+c_{6}\left(2 \rho \dot{\rho} x_{N}^{2}+\rho^{2} 2 x_{N} \dot{x}_{N}\right)
\end{aligned}
$$


ENTHALPY DERIVATIVE

$\begin{aligned} H & ={ }^{n} x_{i} H_{i}\end{aligned}$

$$
\dot{H}=\sum_{i=1}^{n}\left[x_{i}\left(d_{2, i}{ }^{T}+2 d_{3, i} T\right)+x_{j} H_{i}\right]
$$

26 


\section{APPENDIX D}

USER'S GUIDE TO THE CODE

The present version of the code is running at LLL on the 7600 Octopus system. It was compiled under CHAT using TVBOLIB and ORDERL IB in December 1978. It still has a few bugs in certain options but runs most of the cases attempted in several seconds. The code is written in FORTRAN and can be modified easily and recompiled. Since the code was built up by several people, some "deadwood" areas remain. The present controllee is CT5 which immediately creates a drop file, + CT5. This may be referenced by either DBUG or DDT if needed (these are LLL "debug" codes). The teletype interaction and graphics output are specific to LLL and must be modified if used elsewhere. (See Appendix E for complete listing of the code.)

The code is set up to receive input data and instructions via teletype. Upon first entry, the code asks for input feed rate, composition, timing information and some boundary conditions (tank volume, feed temperature, height of overflow, steam pressure, and overflow rate). The overflow rate is used along with steady state assumptions to then compute the calculated steady state conditions pertaining to the input values. The present version of the code assumes that the feed is composed of $\mathrm{HNO}_{3}, \mathrm{H}_{2} \mathrm{O}, \mathrm{PU}\left(\mathrm{NO}_{3}\right)_{4}, \mathrm{~N}_{2} \mathrm{H}_{4}$, $\mathrm{NH}_{2} \mathrm{OH}$, and $\mathrm{Pu}\left(\mathrm{NO}_{3}\right)_{3}$ which reacts instantaneously to form $\mathrm{HNO}_{3}, \mathrm{Pu}\left(\mathrm{NO}_{3}\right)_{4}$ and $\mathrm{H}_{2} \mathrm{O}$ with the generation of heat. We duplicated this scenario to match that of Frogner and Randa $11 .{ }^{2}$ This calculation is done in subroutine FEEDXH and may be modified if one desires to input directly the $\mathrm{Pu}\left(\mathrm{NO}_{3}\right)_{4}$ and water compositions. The reactions proposed also result in a total mole change and the feed rate is modified accordingly. The code prints out the 6 component model fractions and then the total mole factor plus the calculated $\mathrm{Pu}\left(\mathrm{NO}_{3}\right)_{4}, \mathrm{H}_{2} \mathrm{O}$ and $\mathrm{HNO}_{3}$ mole fractions. The code next asks if you want to start with these conditions or input new tank conditions. The user can also request another steady state calculation. If the steady state condition is not valid for the input values or the total time increments $>100$, the code prints a message and recycles for new input. 
After the user specifies the tank conditions, the code asks for new perturbed input values (feed rate, composition-- $\mathrm{Pu}\left(\mathrm{NO}_{3}\right)$ and $\mathrm{H}_{2} \mathrm{O}$--and steam flow rate). A title is then asked for (up to 50 characters allowed--do not put a "1" in column 1) and the code calculates the problem from TINL to TEND in increments of TINC (up to 100 increments allowed). The code then asks for plots desired. Up to 10 plots with arbitrary mapping may be calculated. If al1 10 are wanted, input "-99.", otherwise the plot number followed by the map number should be input. The plot numbers correspond to variables vs times:

$\begin{aligned} \text { Plot \# } & \text { Variable } \\ 1 & \text { Plutonium mole fraction in product } \\ 2 & \text { Nitric acid mole fraction in product } \\ 3 & \text { Water mole fraction in product } \\ 4 & \text { Density }\left(\mathrm{mol}^{3} / \mathrm{m}^{3} \text { ) of product }\right. \\ 5 & \text { Temperature, }{ }^{\circ} \mathrm{C} \\ 6 & \text { Product level in tank, } \mathrm{m} \\ 7 & \text { Nitric acid mole fraction in vapor } \\ 8 & \text { Water mole fraction in vapor } \\ 9 & \text { Density (Kg/m }{ }^{3} \text { ) of product } \\ 10 & \text { Liquid product volume flow rate } \mathrm{m}^{3} / \mathrm{h}\end{aligned}$

The mapping number may be 1-12 and corresponds to the following:

\# $Y, \times$ coord, grid

1 linear, linear, no grid

2 log, log, no grid

3 linear, log, no grid

4 log, linear, no grid

5 linear, linear, full grid

6 log, log, full grid
$\# Y, X$ coord, grid

7 linear, $\log$, full grid

8 log, linear, full grid

9 linear, linear, partial grid

$10 \log _{\text {, }} \log$, partial grid

11 linear, log, partial grid

12 log, linear, partial grid 
Care must be used in selecting the log options since no check for legal values is made. The present system scales according to maximum and minimum values in the plot array and may not be appropriate for log scaling. The current default value of the map number is 9 .

The code next asks if you want another run. If yes, it asks for new input conditions and time and increment values. The user may then continue the problem from the end time of the previous problem or start from the same initial conditions again. If starting from the last problem's state, the user may ask also for continuous plots which means the subsequent graphics will contain the data from the previous run. This way, a series of problems or conditions may be strung together to show many changes. Up to 10 problems may be done this way--each one with up to 100-data increments. When picking the new time and increment, it is assumed that the start time for the new problem is that of the old problem ending time for continuation problems and the old initial time otherwise. If more than 100-time increments are asked for or bad data is input, the code recycles to the appropriate input area and again requests input.

The graphics data is put into an FR80 file type, FX035/TIME and contains a title page with tank and input conditions and the users title, followed by the plotted variables vs time. A final plot is also given of $\log \left(\mathrm{Pu}\left(\mathrm{NO}_{3}\right)_{\mathrm{N}^{--}}\right.$ equilibrium value) vs time. This corresponds to the closed form solution and should yield a straight line with a slope equal to the time constant, if applicable.

The code also generates a file called CANDY1 which is a data file for use in an estimator code. It contains the state variables and time values similar to those plotted in the graphics file.

The code has its own nomenclature, the more important of which are shown below in the order the code asks for them. 


\begin{tabular}{|c|c|c|c|}
\hline Code variable & & $\begin{array}{l}\text { Nomenclature } \\
\text { variable }\end{array}$ & Comments \\
\hline MFIN & $=$ & $M_{f}$ & \\
\hline XIPU & $=$ & $U_{p}$ & $\begin{array}{l}\text { These are actually the } \mathrm{Pu}\left(\mathrm{NO}_{3}\right)_{3} \text { and } \\
\text { water mole fractions of an assumed }\end{array}$ \\
\hline XIW & $=$ & $1-U_{P}-U_{N}$ & $\begin{array}{l}\text { calculates the appropriate } U_{p} \text { and } \\
U_{N} \text { and prints out the above } \\
\text { components and total mole factor which } \\
\text { is the multiplied by MFIN to get } M_{f} \text {. }\end{array}$ \\
\hline TINL & $=$ & Start time & \\
\hline TEND & $=$ & End time & 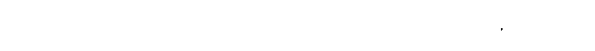 \\
\hline TINC & $=$ & Time increment & $\left(\frac{\text { TEND-TINL }}{\text { TINC }} \leq 100\right)$ \\
\hline MOUT & $=$ & $M_{0}$ & \\
\hline PSTM & $=$ & $\mathbf{P}$ & \\
\hline VOL & $=$ & $v_{0}$ & \\
\hline OVERFLOW HT & $=$ & $\begin{array}{l}\text { Height of overflow } \\
\text { (graphics plotting }\end{array}$ & $\begin{array}{l}\text { pipe } \\
\text { purposes) }\end{array}$ \\
\hline MFIN TEMP & $=$ & Feed temperature & \\
\hline XTPU. & $=$ & $x_{p}$ & \\
\hline XTNA & $=$ & $x_{N}$ & \\
\hline
\end{tabular}




$\begin{array}{ll}\text { Code variabie } & \begin{array}{l}\text { Nomenclature } \\ \text { variable }\end{array} \\ \text { XTW } & =1-X_{P}-X_{N} \\ \text { CTVP } & =\text { Temperature of liquid, T } \\ \text { OMLL } & =P \\ \text { MUAP } & =M_{V} \\ V & =V_{0} \text { conditions in tank } \\ \text { MSTM } & =\text { Steam flow rate, MS }\end{array}$


The following is the teletype output/input for the run that generated the graphics shown in Figs. 4 and 5. Only the first three cases are shown for brevity, but the remainder are similar.

User

Code output

Corments

CT5

Controllee start

Plutonium (IV) Nitrate evaporator. Please

provide the following steady state

information in the units specified. If

you have the variable sequence at hand,

type yes, linefeed, and type in values as

shown in the manual.

Yes

Type in MFIN, XIPU, XIW, TINL

$1966.5,0.005,0.9,0$.

Type in TEND, TINC, MOUT, PSTM

$6 ., 0.1,400 ., 202660$.

Type in VOL, OVERFLOW HT, MFIN

TEMP, $3 F 10.5$

$0.05,2 ., 30$.

6 COMPS ARE

$0.07988 .0 .90000 \quad 0$.

$\begin{array}{lll}0.00524 & 0.00988 & 0.00500\end{array}$

TMOL factor, XIPU, XIW and XINA are

$\begin{array}{llll}1.002 & 0.00499 & 0.93209 & 0.06292\end{array}$

You have input the following steady-

$$
\text { ) }
$$

6 Feed comps assumed

state and initializing parameters

for this job:

Overall feed rate

$=2000.0072 \mathrm{~mol} / \mathrm{h}$

Mole fraction PU in feed $=0,00499$

Mole fraction $\mathrm{H}_{2} \mathrm{O}$ in feed $=0.93209$

Starting time $=0 . \mathrm{h}$

Ending time $=6.0000 \mathrm{~h}$
Calculated 3 comp feed 
Time increment $=0.10000 \mathrm{~h}$

Out flow rate $=400.0000 \mathrm{~mol} / \mathrm{h}$

Steam pressure $=202660.0000 \mathrm{~N} / \mathrm{M} 2$

Are these input values satisfactory?

Yes

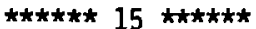

The steam flow rate is $1751.4140 \mathrm{~mol} / \mathrm{h}$

$X T P U=0.02496 X T W=0.83875 X$ XTNA $=0.13629$

CTVP $=116.2280$ OMLL $=41465.7939$

MOUT $=400.0000$ MVAP $=1600.0072$

If you want another SS condition - type AS

If you want SS as input condition - type SS

If you want to input conditions - type IN

IN

XTPU, XTW, VOL conditions in tank, please $0.005,0.932,0.0025$

Now that the tank conditions are set, please provide the pertrubed boundary values in the same units as above. MFIN, XTPU, XTW, MSTM?

$1996.5,0.005,0.9,1750$.

Case 1 Feed and steam

6 Comps are

$0.079880 .90000 \quad 0$.

$0.00524 \quad 0.00988 \quad 0.00500$

TMOL Factor, XIPU, XIW and XINA are

$\begin{array}{llll}1.002 & 0.00499 & 0.93209 & 0.06292\end{array}$

Feed Rate $=2000.0072 \mathrm{~mol} / \mathrm{h}$

Mole fraction of plutonium compound in

Feed $=0.00499$
15 iterations to find SS

SS conditions
Case 1 Initial condition
6 Feed comps to

3 Feed comps conversion 
(Continued)

User

Mole fraction of water in feed $=0.93209$

Steam flow rate $=1750.0000 \mathrm{~mol} / \mathrm{h}$

Are these values correct?

Yes

Type in identification line, please

Start-up from 5\% tank volume--1/31/79

Type in number--NN-of plot wanted, 1-10,

$>10$ to exist

Title of case

Also MM--the * of the map wanted--2F5.1 format

$-99$.

Do all plots option

Time used $=4$ s--015:82:01

Would you like to consider another case?

Run time I0:CPU:SYS

MFIN, XIPU, XIW, MSTM, VOL?

$2096.5,0.005,0.9,1750,0.05$

Change feed rate (case 2)

6 comps are

0.079880 .90000 .

$0.00524 \quad 0.00988 \quad 0.00500$

TMOL FACTOR, XIPU, XIW AND XINA are

$1.002 \quad 0.00499 \times 0.93209 \quad 0.06292$

TEND, TINC?

$8 ., 0.05$

Feed rate $=2100.1829 \mathrm{~mol} / \mathrm{h}$

8.0-h final time

Mole fraction of plutonium compound in feed = 0.00499

Mole fraction of water in feed $=0.93209$

Steam flow rate $=1750.0000 \mathrm{~mol} / \mathrm{h}$

End of complete time period $=\mathbf{8 . 0 0 0 0}$

Time increment $=0.0500 \mathrm{~h}$

Are these values correct? 
(Continued)

User

Yes

Would you like to start from the initial

state conditions (SS), or would you like

to start where the last case (LC) ended

or last case with cont plots (LP)?

LP

Type in identification line, please

Feed rate increase by $5 \%$--run to $8.0 \mathrm{~h}$

Type in number--NN-of plot wanted, 1-10,

$>10$ to exist

Also MM--the * of the map wanted--2F5.1 format

$-99$.

Time used $=2$ s- $-025: 74: 00$

Would you like to consider another case?

Yes

MFIN, XIPU, XIW, MSTM, VOL?

$2096.5,006,0.9,1750 ., 0.05$

Change $\mathrm{PU}\left(\mathrm{NO}_{3}\right)_{4}$
value (Case 3$)^{4}$

6 comps are

0.078880 .900000$.

$\begin{array}{lll}0.00524 & 0.00988 & 0.00600\end{array}$

TMOL factor, XIPU, XIW and XINA are

$\begin{array}{llll}1.001 & 0.00599 & 0.93337 & 0.06063\end{array}$

TEND, TINC?

$10 ., 0.05$

Feed rate $=2098.7852 \mathrm{~mol} / \mathrm{h}$

10.0-h final time

Mole fraction of plutonium compound

in feed $=0.00599$

Mole fraction of water in feed $=0.93337$ 


\section{(Continued)}

Steam flow rate $=1750.0000 \mathrm{~mol} / \mathrm{h}$

End of complete time period $=10.0000$

Time increment $=0.0500 \mathrm{~h}$

Are these values correct?

Yes

Would you like to start from the initial state conditions (SS), or would you like to start where the last case (LC) ended or last case with Cont Plots (LP)?

LP

Type in identification line, please include all previous data in graphics

Feed composition changed 20\%--run to $10 \mathrm{~h}$ Title of case

Type in number--NN--of plot wanted, 1-10, $>10$ to exit

Also 1 --the * of the map wanted--2F5.1 format

-99.

Time used $=2$ s--024:75:00

Would you like to consider another case?

...etc 


\section{APPENDIX: E}

\section{CODE LISTING}

The code consists of several subroutines. Some important ones are:

MAIN: Initialization and control of all case calculations. Computes steady state values and calls the Gear driver and plot subroutine.

PLOTRD: Plotting subroutine--entered to ask for title line and 'plors graphics as directed. (Called by MAIN.)

VPSH: Calculates overflow condition and resets volume if needed. (Called by DRIVE.)

DIFFUN: Heart of calculation of state derivatives. Produces current value of derivative based on state variables and present boundary conditions. (Called by DRIVE.)

ENTHCAL: Computes the enthalpy of liquid and vapor.

FEEDXH: Computes the feed composition and heat effects for six component feed. (See Appendix D)

GMLQDN: Computes the liquid density and boiling temperature.

PEDERV: Dumy subroutine needed by Gear package.

VAPCOMP: Computes vapor mole fractions

DRIVE: Main control and driver for the Gear package.

The code listing is in the attached fiche. 


\section{REFERENCES}

1. J. V. Candy and R. B. Rozsa, Nonlinear Estimators, etc., Lawrence Livermore Laboratory, Livermore, Ca. (to be published).

2. B. Frogner and K. Randall, Final Report: Characterization and Modeling of a Plutonium Concentrator, Lawrence Livermore Laboratory, Livermore, Ca., UCRL-13864 (1978).

3. G. K. Patterson and R. B. Rozsa, DYNSYL: A General Purpose Dynamic Simulator for Chemical Processes, Lawrence Livermore Laboratory, Livermore, Ca., UCRL-52561 (1978).

4. R. Castleton and J. V. Candy, DYNEST, A Dynamic Estimator Calculation Program, Lawrence Livermore Laboratory, Livermore, Ca., UCRL-52573 (1978).

5. A. C. Hindmarsh, GEAR, Ordinary Differential Equation System Solver, Lawrence Livermore Laboratory, Livermore, Ca., UCID-30001, Rev. 3, (1974).

6. A. Maimoni, Lawrence Livermore Laboratory, private communication (1977).

7. R. A. daRoza, Lawrence Livermore Laboratory, private communication (1977).

EHB:mab 